WellBeing International

WBI Studies Repository

$6-2002$

\title{
The Future of Stock Enhancements: Lessons for Hatchery \\ Practice from Conservation Biology
}

Culum Brown

University of Cambridge

Rachel L. Day

University of Cambridge

Follow this and additional works at: https://www.wellbeingintlstudiesrepository.org/acwp_aff

Part of the Animal Studies Commons, Nature and Society Relations Commons, and the Population Biology Commons

\section{Recommended Citation}

Brown, C., \& Day, R. L. (2002). The future of stock enhancements: lessons for hatchery practice from conservation biology. Fish and Fisheries, 3(2), 79-94.

This material is brought to you for free and open access by WellBeing International. It has been accepted for inclusion by an authorized administrator of the WBI Studies Repository. For more information, please contact wbisr-info@wellbeingintl.org.

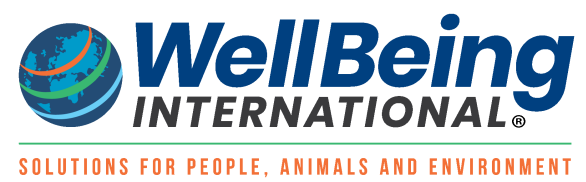




\title{
The Future of Stock Enhancements: Lessons for Hatchery Practice from Conservation Biology
}

\author{
Culum Brown \& Rachel L. Day \\ University of Cambridge
}

\section{KEYWORDS}

conservation biology, fisheries, hatcheries, reintroduction, restocking

\begin{abstract}
The world's fish species are under threat from habitat degradation and over-exploitation. In many instances, attempts to bolster stocks have been made by rearing fish in hatcheries and releasing them into the wild. Fisheries restocking programmes have primarily headed these attempts. However, a substantial number of endangered species recovery programmes also rely on the release of hatcheryreared individuals to ensure long-term population viability. Fisheries scientists have known about the behavioural deficits displayed by hatchery-reared fish and the resultant poor survival rates in the wild for over a century. Whilst there remain considerable gaps in our knowledge about the exact causes of postrelease mortality, or their relative contributions, it is clear that significant improvements could be made by rethinking the ways in which hatchery fish are reared, prepared for release and eventually liberated. We emphasize that the focus of fisheries research must now shift from husbandry to improving post-release behavioural performance. In this paper we take a leaf out of the conservation biology literature, paying particular attention to the recent developments in reintroduction biology. Conservation reintroduction techniques including environmental enrichment, life-skills training, and soft release protocols are reviewed and we reflect on their application to fisheries restocking programmes. It emerges that many of the methods examined could be implemented by hatcheries with relative ease and could potentially provide large increases in the probability of survival of hatchery-reared fish. Several of the necessary measures need not be time-consuming or expensive and many could be applied at the hatchery level without any further experimentation.
\end{abstract}

\section{Introduction}

The role of hatcheries in maintaining fish stocks

The world's fish species are under threat from habitat degradation and over-exploitation. In many instances, attempts to bolster stocks have been made by rearing fish in hatcheries and releasing them into the wild. In response to the rapid decline in fish numbers, hatcheries breed, rear and release billions of fish annually. It has been estimated (Welcomme and Bartly 1998) that well over 300 species worldwide are involved and every country contributes to some extent. Of these 300 or so species $290+$ are freshwater (Welcomme 1992); therefore, marine stocking is still relatively uncommon. The amount spent annually on rearing and releasing hatchery fish is yet to be estimated, but there is little doubt that the total 
annual bill runs into billions of dollars. The number of hatchery-reared Atlantic salmon released every year, for example, is well over 5 billion. A conservative estimate of the number of hatchery-reared Atlantic salmon released in the UK during the year 2000 was around 8 million, $98 \%$ of which were released in Scotland. In 1996, Iran released over 12 million sturgeon (Acipenser oxyrinchus, Mitchill), 2.5 million perch (Perca fluviatilis), 100 million bream (Abramis brama, L.) and 140 million mahi sephid (Rutilus frisii, Nordmann) (Abdolhay 1996). These figures are almost certainly dwarfed next to the figures from North American, Japanese and Nordic regions (see Welcomme and Bartly 1998 for a review of the extent of fishery enhancements and Fushimi 2001 for a review of Japanese stock enhancement programmes specifically).

Despite these massive releases, in most cases there has been little change to the abundance of target species entering the fishery (Coleman et al. 1998; Svasand et al. 2000).With few exceptions, the results of restocking from hatcheries have either been poorly monitored or considered unsuccessful in the few cases where impact of release has been monitored (Svasand et al. 2000). Salvanes (2001), for example, questions the underlying assumption that humans have reduced many fish stocks below carrying capacity and that the release of captive-reared juveniles will lead to an increase in the number of adults and thus recruitment into the fishery. For the most part, scientific assessment of this assumption has been considered too difficult to address and has largely been ignored. In the case of marine species there is a scarcity of data relating to the movements of fish, natural mortality rates and most other aspects of their behaviour and ecology.

The first step in evaluating the success of a reintroduction programme aught to stem from biological/scientific studies (Lindburg 1992). These must estimate the survival of released fish, the principal causes of mortality, their contribution to subsequent generations (and resident gene pools), and perhaps even the impact on the environment as a whole. Secondly we may wish to determine if releases from hatcheries are economically feasible. If not, then it may be possible to alter hatchery practices in order to redress the balance. Recent studies into the enhancement of cod stocks (Svasand et al.2000) and advances made in the Japanese flatfish hatchery programmes (Hossain et al.2001) provide clear examples of how a greater scientific understanding of the behavior and ecology of the species in question and long-term intensive monitoring provide greater insight into the shortfalls of hatchery programmes. Further, they provide clear suggestions as to how the efficiency of the industry can be improved and moved towards economic viability.

While restocking is widely used as a fisheries management tool, it has also been used for the conservation and management of threatened species (e.g. Flagg et al.1995). In 1990, 27\%of all federal recovery programmes for endangered freshwater fish in the USA included captive breeding as one of the recovery components (Andrews and Kaufman1994). For example, steelhead trout (Oncorhynchus mykiss) were recently listed under the US Endangered Species Act and the recovery programme relies heavily on hatchery-reared individuals for restocking (Berejikian et al.2000).

\section{Restocking versus reintroduction}

Fisheries management and conservation biology have remarkably similar agendas as both seek the longterm viability of fish stocks albeit for different reasons. Conservationists are interested in maintaining biodiversity whilst fisheries managers are interested in maximizing productivity. In the case of the conservation biologist, the establishment of self-sustaining populations in the wild is a principal objective. While this would also be ideal for fisheries managers, providing a stable return to the industry is a priority. In the former case, survival to reproductive age is imperative; in the latter, however, survival to a required size for capture is important and this size may or may not contribute to the establishment of selfsustaining populations. Conservationists may, therefore, be prepared to invest more time and money in 
the production of ecologically viable juveniles for release, but we emphasize that both groups should ultimately be looking to improve post-release survivorship.

Surprisingly, the practical methods utilized by each group are worlds apart, perhaps reflecting the difference in emphasis. Conservation biology has long emphasized the importance of practices such as environmental enrichment, pre-release training programmes and soft release to improve the post-release survivorship of captive-bred animals (see Beck et al. 1994 for summary statistics). In contrast, the production of ecologically viable individuals is not part of the hatchery equation because the production of large quantities of fish, rather than natural history, behaviour and ecology, largely guides hatchery practices (Johnsson 1993; Fushimi 2001). Agersborg (1934) states that rapid growth and high survivorship within the hatchery have been the fundamentals of aquaculture for years. This position still reigns supreme today. Many hatcheries are government funded or at least heavily subsidized. The level of success, and hence funding is often being determined by the number of fish released rather than by the survival rates of those fish or the return to anglers and the industry.

\section{Hatchery shortfalls}

While hatchery-rearing techniques have been perfected over the last few decades and continue to provide more and more fish for release, the proportion of fish surviving to adulthood is in decline (Nickleson 1986; Beamish et al. 1992; Pearcy 1992; Coleman et al. 1998; Blaxter 2000). In the case of salmonids typically, less than $5 \%$ of all hatchery-reared fish make it to adulthood (McNeil 1991). In UK, the number is more likely to be below $3 \%$ and for many other species released from hatcheries the figure is commonly far lower (e.g. chum salmon 1-3\%, and < 1\% for cod; Salvanes 2001). At first glance these statistics seem little different from the rates observed in wild fish. However, if we examine age-specific mortality, bearing in mind that most species are reared in captivity for extended periods and released between 6 months and 2 years of age, then we see that captive-reared fish do very poorly indeed (Reisenbinchler and McIntyre1977; Chilcote et al.1986; Leider et al.1990). It has been estimated that the mortality rate of released cod is at least twice that of wild juveniles (Svasand et al. 1989). Captive-reared Japanese flounder (Paralichthys olivaceus) also show massive levels of mortality in the first few days after release (only $10 \%$ make it to 10 days post-release) primarily due to the loss of fish that lack appropriate pigment patterns (Blaxter 2000) and inappropriate antipredator responses (Furuta 1996). Even when age-specific mortality is not taken into consideration, Wiley et al. (1993) suggest that stocked fish still show lower survival from eggs to catchable sizes than their wild counterparts. Most of the mortality occurs in the first few days following release rather than over the subsequent months (Howell 1994; Blaxter 2000; Svasand et al. 2000). These figures are exactly what one would expect given the methods currently employed during hatchery rearing and release and are indicative of predator-mediated mortality. If hatchery-reared fish manage to survive their first week or so in the wild, then the chance of long-term survival is greatly increased (Kanid'hev et al. 1970; Brown and Smith 1998). This brief time following release represents a prime target period towards which future research efforts should be directed.

The relatively poor success rate of restocking and various other environmental issues (for example, loss of genetic integrity of wild stocks) have led to a fierce debate regarding the value of hatchery supplementation programmes (see Winton and Hilborn 1994 for further discussion). It is worth highlighting the fact that hatcheries must give careful consideration to the choice of brood stock if genetic 'pollution' of the resident wild stock is to be prevented (Utter 1998; Doyle et al. 2001). Ideally, a large number of mature individuals should be sourced from the target population every year. In some instances (e.g. salmon hatcheries in UK), brood stock are captured during local spawning runs every season, but this appears to be the exception rather than the rule. In contrast, managers working on the conservation programme for the Mary River cod (Maccullochella peelii) in Australia go to a considerable effort to 
maximize the genetic diversity by constantly turning over the brood stock (Simpson and Jackson 1996). Releases of fish species outside their natural range (introduction as opposed to reintroduction) for fisheries purposes aught to be strongly discouraged or at the very least strictly controlled. Although the IUCN guidelines for the translocation of animals do not have the scope to address the introduction of exotic species for fisheries purposes, they do nevertheless provide a reasonable lead as to the types of issues that aught to be addressed prior to introduction.

All other issues aside, there is little doubt that poor survival of hatchery-reared fish is a major concern as it greatly reduces the efficiency of using hatchery stocks to supplement wild production whether for commercial or conservation means (Mesa 1981; Sproul and Tominaga 1992; Maynard et al.1995; Olla et al. 1998). Nevertheless, hatchery supplementation of wild stocks looks set to play a major role in maintaining the sustainability of many fisheries stocks for the foreseeable future. Furthermore, restocking or reintroduction programmes seem set to aid in the conservation management of endangered fish species especially when utilized in concert with habitat preservation and restoration (e.g. Secor and Houde 1998). Finally, releasing fish into the wild knowing they are totally unprepared for survival and the majority will die, presents a considerable ethical conundrum that ought to be addressed. In order to move forward the focus of hatchery management must now switch from husbandry to improving the postrelease survival chances of hatchery-reared fish.

\section{Identifying specific problems}

Fisheries biologists have known for years that hatchery-reared individuals show substantial deficits in virtually all aspects of their behaviour (see Stone 1872 and Lord 1934 for example). As early as the forties, Fish (1940) recognized that hatcheries circumvented natural selection in order to artificially boost hatchery survival. Arguably the two most important behaviours any animal must develop are the ability to eat and avoid being eaten. Early attempts to raise enough wild prey to maintain hatchery populations proved impossible and the focus quickly turned to developing artificial food sources (Embody and Gordon 1924). Hatchery-reared fish are now routinely reared on a mundane diet of man-made pellet foods that require limited use of potential foraging behavioural repertoires as there is no variation in the timing, location, abundance or type of food on offer. Hatchery-reared Japanese flounder, for example, are fed at the surface, which induces an unnaturally high level of 'off the bottom swimming activity' post-release, thus increasing their susceptibility to predators (Furuta1996).

Laboratory experiments show that foraging behavior is reliant on learning from prior experience (e.g. Paszkowski and Olla 1985; Stradmeyer and Thorpe 1987; Reiriz et al.1998). Learning enables individuals to improve their prey recognition, attack mode and handling efficiency and is especially important when foraging in the wild as it can improve foraging efficiency by adjusting foraging behaviour to match contemporary circumstances (Hughes et al. 1992). These foraging behaviours are particularly important when the distribution, abundance and trophic value of prey are variable. Little wonder then, that upon release, hatchery fish often show dramatic deficits in their foraging behaviours. Following release many captive-reared fish may not eat at all for several days (Paszkowski and Olla1985), weeks (Miller 1954) or up to a month (Usher et al. 1991).When they do start to forage, they typically take up high risk and energetically costly positions close to the surface of the water and in regions of high flow (e.g. red drum (Sciaenops ocullatus): Stunz et al. 2001). They often fail to disperse, are less aggressive and consequently are frequently found in unsustainably high densities having to compete heavily for limited resources (Olla et al. 1998). Often the released fish show limited prey choice, take fewer items and are very slow to switch between prey types compared with wild fish (Sosiak et al. 1979; Ersbak and Haase 1983). As a result hatchery-reared fish show substantial weight loss compared to transplanted wild fish and their mortality rates can be up to 10 times greater than that of wild fish (Miller 1954). 
As with foraging behaviour, the antipredator behaviours of hatchery-reared fish are equally poorly developed and insufficient to cope with life in the wild. Fish reared in captivity are completely predator naïve because they are provided with no opportunity to interact with predators prior to release. Predation is thought to be the principal cause of mortality among released hatchery fish (Howell 1994); however, fish weakened by starvation are also more prone to risk taking and likely to fall victim to predation. There are three key behaviours that are important to develop if predator-induced mortality is to be reduced. The first involves avoidance strategies that reduce the probability of encountering predators (e.g. avoiding dangerous microhabitats, behaving cryptically or taking on cryptic colouration). The second is predator recognition and detection and the final behaviour is the antipredator response (schooling, fleeing to refuge, etc.) Like foraging behaviour, there is ample evidence that antipredator behaviour improves considerably with experience (Kanayama and Tuge 1968; Fraser 1974; Olla and Davis1989; Csanyi and Doka 1993; Jarvi and Uglem 1993; Berejikian 1995; Brown and Smith 1996; Mirza and Chivers 2000; Hossain et al. 2001). Prior exposure is therefore vital to the development of effective antipredator behaviours and the improved viability of restocking procedures.

\section{Finding a solution}

In the process of addressing the problem of post-release mortality, much can be gained by reviewing the conservation biology literature. There are now numerous texts available that highlight the importance of ecology and behaviour in conservation management and more specifically in reintroduction biology (Olney et al. 1994; Clemmons and Buchholz 1997; Caro 1999a; Gosling and Sutherland 2000). One of the key aspects of a successful reintroduction is to ensure that the rearing environment is such that nearnatural behaviours can develop during the period of captivity (Carlstead 1996; McLean 1997). The conservation of behavioural diversity should not be neglected (Buchholz and Clemmons1997) especially in species where different populations exist that inhabit slightly different environments (e.g. salmon runs). Generally speaking, providing that husbandry techniques are good and result in healthy young then survival in captivity is guaranteed. If, however, the intention is to release the animals into the wild, behavioural considerations rather than husbandry must become a priority (Wallace 2000). Olla et al. (1994) suggested that it is 'critical . . . to develop methodologies for hatcheries to improve post-release behavioural performance'.

As early as 1965 it was recognized that fisheries research ought to be redirected at reducing post-release mortality rather than continuing to focus on mass production and release (Haskell 1965). Ultimately the aim of the hatchery should be to produce animals that are behaviourally, morphologically, physiologically and genetically similar to those in the wild (Brown and Laland 2001; Fushimi 2001). For the most part, selective breeding has effectively resulted in the production of domesticated strains of fish that are well adapted to life in captivity, which is far removed from the selective pressures of life in the wild. The development of behavioural patterns is heavily dependent on the ongoing and complex interaction between the environment and an individual's genotype (Alcock 1993). Those behaviours that rely on this interaction cannot develop correctly if the rearing environment differs to that in which the animal is destined to be released. It follows quite naturally therefore, that development in a dull, artificial rearing environment will result in individuals who are unprepared for life in the wild (Derrickson and Snyder 1992).

There are at least six major areas of behaviour that should be considered in the development of any scheme whose ultimate aim is release into the wild (Kleiman 1996).To survive candidates for reintroduction must be able to (i) avoid predators; (ii) acquire and process food; (iii) interact socially with conspecifics; (iv) find or construct shelters or nests; (v) locomote on or in complex terrain; and (vi) orientate and navigate in a complex environment. Thus, in order to design more natural rearing environments it is essential to have a broad understanding of the biology and ecology of the fish species in question and especially of the environment into which the animal is to be released (Kleiman et al. 
1994). For the most part, these details are likely to be not only species but also case-specific. For example, it is vital to know the types of predators and food items the individual is likely to encounter at the site of release. These details are likely to show considerable geographical variation even within a catchment. The degree of sociality may also play a considerable role in the success of release programmes (Wallace 2000). Prior social experience can have significant influences on future levels of aggression and dominance rank (Hojesjo et al. 1998). Many fish species are highly social and form shoals or schools for some or most of their lives. Others, however, are more solitary and may defend territories. In the former case, release in large groups would provide the best results, but for the latter, scatter seeding would be a better approach. For those species that have more complicated social relationships, such as the development of harems, density- or size-dependent hermaphrodites, etc., more attention must be paid to the demographic composition of the release groups.

For some fish early exposure to appropriate cues during sensitive periods at some stage in development is essential for ensuring appropriate behavioural responses later in life. Whilst imprinting (Lorenz 1952) has been shown to be extremely important in the social welfare of birds (Bolhuis 1991) and in reintroduction techniques (e.g. Wallace and Temple 1987; Lewis 1990), less is known about these periods in fish. Habitat imprinting is well known in salmonids that imprint on the chemical cues in their natal streams during critical stages of their development and later use these cues to navigate their way back to natal streams in order to breed. It seems likely that eels may rely on similar techniques. Less is known about sexual imprinting in fish but evidence from those fish that have some degree of parental care suggests that early exposure to appropriate 'sexual models' provides later guidance during mate choice (Weber and Weber 1976). Species cross-fostering experiments seem to indicate that exposure to sexual models may even be important in fish that do not show parental care (Korner et al.1999). In these cases familiarity appears to play a large role in a fish's choice of social and sexual partners. These considerations are especially important if released fish are going to go on and breed in the wild, thus amplifying the initial investment in pre-release training whilst forming a self-sustaining population.

\section{Management techniques}

The conservation reintroduction literature suggests three principal management techniques, the implementation of which is recommended for a successful reintroduction programme. In most cases some combination of each of these three techniques is utilized. Determining the relative merits of each is often difficult particularly when working with endangered mammals or birds. Working with fish, however, should provide the ideal opportunity to assess the relative importance of each technique because of the large number of individuals that can be released. Such an experimental approach to assessing reintroduction techniques has long been called for by conservation biologists (Lindburg 1992; McLean 1997; Caro 1999b; Wallace 2000) and may provide useful information for all endangered species programmes.

\section{Environmental enrichment}

Environmental enrichment has come to mean many things in the reintroduction literature. It can simply mean increasing the structural complexity of the environment to relieve boredom or to provide a taste of the habitat the animal is likely to be exposed to in the wild (Shepherdson 1994; Miller et al. 1996). For example, lion tamarins (Leontopithecus sp.) have been given an opportunity to move around on natural vegetation prior to release (Beck et al.1991) and providing wild cats with live fish or hidden food encouraged natural predatory tendencies and substantially reduced stereotyped pacing (Shepherdson et al.1993).

For the most part, hatchery environments are completely devoid of structure. They tend to comprise of a featureless, monotonic enclosure with no opportunity to escape from conspecifics or display any other 
natural behaviour. They bear no resemblance whatsoever to the fish's natural environment and densities can be up to 100 times greater than those in nature. Reductions in density alone seem to have mixed results on post-release survival but it appears that intermediate densities produce better quality fish (Wiley et al.1993). Many of the captive-breeding programmes for mammals allow the animals to experience realistic natural environments, or at the very least alternative habitats that contain some naturalistic features of the environment into which the animals are to be released (e.g. Beck et al. 1991; Biggins and Thorne 1994). Preliminary work where hatchery- reared fish are released into outside ponds prior to release suggests that brief exposure to this type of naturalistic environment improves survival rates substantially (e.g. Maynard et al. 1996). Naeslund (1992) found that brown trout (Salmo trutta) reared in outside ponds survived better when released into streams than standard hatchery-reared fish. In these situations the fish are not only exposed to natural temperature and light fluctuations and more complex habitat structure, they are also exposed to limited supplies of live prey and avian predation pressure. Similarly, fish provided with some cover in the hatchery showed increased growth and survival within the hatchery (Leach 1926).

These types of enrichment are likely to translate to greater survival post-release. Providing submerged structure creates visual isolation amongst potential competitors allowing the establishment of territories through improved visual references, leading to lower levels of aggression and improved growth rates (Mesick 1988). It has previously been suggested that simple measures like increasing flow rates within races to match wild conditions, providing dark backgrounds, semi-natural stream beds, submerged structure, and overhead cover could improve survival rates upon release (Leonard and Cooper 1941; Ritter and MacCrimmon 1973; Leon 1975; Butler 1981; Howell and Baynes 1993;Wiley et al. 1993; see Maynard et al. 1995 for a review). For example, Howell (1994) suggests that reduced opportunity for exercise in hatchery conditions leads to a reduced ability to flee from predatory strikes. Whilst Berejikian et al. (2000) found that steelhead trout provided with an enriched environment in the form of in-water structure, under-water feeders and overhead cover achieved a higher social rank and growth rate when mixed with conventionally reared fish.

\section{Life-skills training}

Life-skills training provides training regimes designed to alter the nature of an animal's behavior or teach essential life skills (Brown and Laland 2001). Many behaviours require some degree of learning (see McLean 1997 for a review of learning and relevance to conservation reintroductions), which can only come about by repeated exposure to appropriate stimuli. In some animals social learning, for example via parental guidance, is necessary for the development of behaviours. Social guidance is particularly important in long-lived, highly social animals such as primates (Mineka and Cook 1988; Box1991), elephants (Schulte 2000) and killer whales (Guinet and Bouvier 1995); however, it is by no means restricted to these taxa. Recent investigations into the occurrence of social learning suggest that it is a common and widespread phenomenon among many social species and is by no means restricted to 'higher order' or more 'clever' species. In fact, there is ample evidence that social learning plays a role in the development of many behaviours amongst fishes (Suboski and Templeton 1989; Brown and Laland 2001). Housing captive-reared individuals with more skilled conspecifics to demonstrate behaviours that are important to survival is a common reintroduction training technique (Kleiman 1989; Dobrott 1993).

Irrespective of the mode of learning, prior exposure to live prey (Morgan-Davies 1980; Phillips et al. 1995; Vargus and Anderson 1998) and potential predators (Carpenter et al. 1991; Maloney and McLean 1995; McLean et al. 1996; see Griffin et al. 1999 for a review) is a common practice in most conservation reintroductions, yet there are only a few studies investigating these types of experiences in hatcheryreared fish and the effect it might have on post-release survival (Jarvi 1990). Even if non-live prey is provisioned, it may be hidden or embedded thus encouraging the animals to work for their food and in this 
way they may be primed to actively search for and catch live prey upon release. For example, swift foxes (Vulpes velox) were pre-adapted to natural foods by being provided with road-killed ungulates rather than pre-prepared meat (Scott-Brown et al. 1986). When food is added to the hatchery enclosure, limited searching is required to discover it, thus providing no opportunity for the fish to develop natural foraging behaviours.

It would be relatively easy to stimulate foraging behaviour in fish, without the use of expensive live bait, by using similar techniques as those outlined above. Alternatively, live prey may be introduced periodically or just prior to release to provide the fish with limited foraging experience with minimal time and monetary cost.

In fact, improvements in foraging behaviour have been shown to occur with repeated exposures (Godin 1978; Ringler 1979; Paszkowski and Olla 1985; Stradmeyer and Thorpe 1987; Reiriz et al. 1998). Improvements can be made in prey recognition, handling and selection (Ware 1971; Croy and Hughes 1991; Hughes et al. 1992). More complex foraging behaviours such as weighing up the costs and benefits associated with foraging under different levels of predation threat (Dill and Fraser 1984; Metcalf et al. 1987; Gotceitas and Godin 1993) and selective foraging based on trophic value and abundance can also be improved with experience (Hughes et al.1992; Provenza and Cincotta1993; Reiriz et al.1998).

As early as 1966, Thompson (1966) was conducting experiments to determine if coho (Oncorhynchus kistuch) and chinook salmon (O. tschawytcha) could be conditioned to avoid a model predator by using electric shocks as negative stimuli. Subsequent tests conducted in large aquaria containing live predators showed that conditioned fish had a $50 \%$ increase in survival rate compared with control groups. Other studies conducted by Kanayama (1968) on chum salmon (O. keta) and Ginetz and Larkin (1976) using sockeye salmon (O. nerka) showed similar results. Experiments conducted by Olla and Davis (1989) found that prior exposure toa predator increased survival rates substantially on subsequent exposure (see also Hossain et al. 2001). It is now well established that prior experience with predators greatly improves antipredator responses in fish (Olla and Davis 1989; Magurran 1990; Kieffer and Colgan 1992; Jarvi and Uglem 1993; Berejikian 1995; Brown and Smith 1998; Brown and Warburton 1999). Fish may even show improved survivorship simply by interacting with predator-experienced individuals (see Patten 1977; Suboski and Templeton 1989; Wiley et al. 1993; Brown and Laland 2001). Jarvi (1990) showed that acclimation by Atlantic salmon to salinity levels and predators reduces stress and increases survivorship. Similarly, Jarvi and Uglem(1993) exposed hatchery-reared Atlantic salmon to cod either behind a partition or allowed them to directly interact with the hunting predator. In both instances antipredator responses were more appropriate than control groups on later exposure.

Both Suboski and Templeton (1989) and Brown and Laland (2001) suggest that for aging and predator avoidance training regimes could be implemented at the scale required for hatcheries. Certainly the pattern of post-release mortality observed in released fish implies that pre-release training should occur relatively quickly, as those that do survive the early post-release period must have rapidly acquired the necessary life skills in order to survive. This line of evidence combined with avoidance retention experiments (Brown and Smith 1998; Berejikian et al.1999) suggests that pre-release training would not have to be an extensive, time-consuming process and providing that sensitive periods for learning are not jeopardized, need only be initiated shortly before release. Even a single exposure to predators may make a substantial difference to the behaviour of prey on subsequent exposures (Olla and Davis 1989; Pyanov 1993; Hossain et al. 2001)

Hard versus soft release 
For the most part, traditional hatchery release practices transport the fish in large drums and simply dump the fish directly into the water body to be stocked. This process is often referred to as 'hard release' in the conservation biology literature. In stark contrast, many conservation programmes rely on a protocol called 'soft release'. In some cases the term 'soft release' has been used more broadly referring to the provision of any kind of training or preparation for release (pre- or post-release conditioning: Scott-Brown et al.1986). Here we use the term far more restrictively referring solely to the practice of providing an acclimatization period at the release site (or close by) prior to liberation.

Soft release enables the animals to become accustomed to the prevailing environmental conditions (temperature and chemical composition of the water, for instance), familiarize themselves with local landmarks for orientation and navigation, recover from transportation, and develop cohesive social bonds wherever appropriate. For example, in the red wolf (Canis rufus), animals that survived for the longest periods of time following release were those who had experienced longer acclimatization periods (Phillips et al.1995). Reports of disorientation following 'hard release' are common in the conservation biology literature (Kleiman et al. 1986). Vincent (1960) estimated that $10 \%$ of released fish appeared to be disorientated upon release, swimming into rocks, sandbars and even out of the water.

There is, however, already good evidence that an acclimatization period would greatly enhance hatchery fish survival upon release. It has been reported that coho smolts given less than 90-min recovery time showed lower survival rates than unstressed control groups (Olla et al. 1992), whilst Lagardere et al. (1988) and Goodyear (1973) both suggest that it takes around 3 days for fish to familiarize themselves with their new environment. Such familiarization can have unexpected benefits. For example, guam (Rallus owstoni) held in staging pens to adjust to the climate also benefited from natural prey passing freely through the pens providing them with time to acquire an appropriate search image whilst being protected from predation (Derrickson 1986). Also, preliminary studies suggest that if brown trout are held in enclosures in the river for 6 days at the site of release, prior to liberation, growth rates and recapture rates can be significantly improved (Jonssonn et al. 1999). Similarly, holding brown trout in enclosures for $24 \mathrm{~h}$ at the site of release had a positive effect on the number of fish recaptured (Cresswell and Williams 1983).

There is a large body of evidence showing that transportation has a significant effect on the stress levels of hatchery fish. Importantly, elevated stress levels have been associated with increased susceptibility to predators (Olla and Davis 1989; Jarvi 1990; Lepage et al. 2000), a reduced ability to learn (Olla et al. 1992), increased susceptibility to infections (Shepherd and Bromage 1992), changes in social behaviour (Ejike and Schreck 1980) and a reduced ability to cope with fluctuations in temperature and water chemistry (Strange et al. 1978). Physiological recovery from chronic stress is fairly rapid, occurring over a matter of hours; however, recovery of behavioural traits like aggression, territoriality and learning ability probably takes several days to weeks (Schreck et al. 1997). The length of time allowed for acclimatization, therefore, is likely to be positively correlated with improved survival for the short term (up to 7 days), but as time goes on negative effects (such as density-related aggression and reduced dispersal) may begin to offset the benefits of prolonged containment (Kaya and Jeanes 1995). Allowing an intermediate acclimatization period prior to liberation should, therefore, result in substantial reductions in post-release mortality. The exact length of acclimatization time required to maximize survival is again likely to be species-or case-specific and would be a profitable field for further experimentation. 


\section{Lessons learnt from hatchery releases}

\section{Release site characteristics}

For the most part, much is already known about choosing the right location and the time of year for the release of captive-reared fish especially with reference to flow rates, habitat quality (including stream-bed structure), prey, predator and competitor abundance, etc. (Leber et al. 1996; Jokikokko 1999; see Cowx 1998 for a review). There are excellent recommendations set out by the IUCN as to when, where and how reintroductions should occur (IUCN/SSC Guidelines for Reintroductions 1995; and IUCN Position Statement on Translocation of Living Organisms 1987). We would, however, like to draw the reader's attention to the IUCN directives of reintroduction and restocking protocols (IUCN 1995, 1987, respectively) and suggest that these guidelines could certainly be helpful when establishing how best to release hatchery-reared fishes. In light of the abundant information already available on this topic we shall address this issue somewhat superficially paying particular attention to the potential complications of the existence of a remnant resident population, because success rates of hatchery releases are often correlated with the existence of resident populations (Welcomme and Bartley 1998).

The existence of a resident population often suggests that supplementation may be less successful due to further complication of social interaction of the resident and introduced fish. Laboratory studies suggest that hatchery-reared fish may be more aggressive than their wild counterparts (Swain and Riddell 1990; Berejikian et al. 1996), leading to the concern that hatchery fish could potentially displace wild stocks (see Nickelson et al. 1986). However, prior residency conveys an advantage to the resident during aggressive interactions (Caballero and Castro 1999; Volpe et al. 2001), possibly accounting for the lack of evidence that displacement actually occurs in the wild (Deverill et al. 1999).With few exceptions, hatchery releases continue to fail to make substantial contributions to resident populations possibly due to their inability to cope with competition from residents and the high levels of mortality that they sustain (Fenderson and Carpenter 1971; Bachman 1984). The provision of habitat enrichment during rearing at the hatchery may provide the key to the development of more natural social behaviours that could potentially alleviate some of the social inadequacies displayed by hatchery fish.

The absence of a resident population, on the other hand, may be indicative of an unsuitable reintroduction site as it suggests environmental degradation or extreme fishing pressure (see the reintroduction efforts of sturgeon in Chesapeake Bay for example: Secor et al. 2000). In these cases, it may be pertinent to address habitat restoration issues in concert with a reintroduction effort. From a conservation management perspective it is important to firstly manage any threatening processes prior to reintroduction or restocking (IUCN1987, 1995). In the case of fisheries, however, the threatening process (i.e. fishing) is encouraged and may be the sole reason why the restocking is taking place and, ironically, may be funding it.

\section{Size at release}

The few studies that have monitored the survival rates of hatchery-reared fish all seem to come to the same conclusion: the size of the fish at release is a critical factor in determining the probability of survival. Generally larger fish have a higher survival rate. Mortality of small cod $(<25-30 \mathrm{~cm})$ is responsible for the decrease in numbers of released fish (Svasand et al. 2000). When juvenile Japanese flounder are released, they typically range from 4 to $12 \mathrm{~cm}$ long and only those larger than $9 \mathrm{~cm}$ survive and go on to grow to a commercial size (Masuda and Tsukamoto 1998). Similarly, red sea bream over $4 \mathrm{~cm}$ at release go on to contribute to the catch (Tsukamoto et al. 1989). A recent review of inland fish stock enhancement in China suggests that grass carp greater than $10 \mathrm{~cm}$ in their second year of life have a much greater chance of survival (Li 1999). It is because of this size-correlated mortality that hatcheries 
grow fish in captivity for extended periods prior to release. However, the size at which fish are released is also governed by economic constraints. The longer the fish remain in captivity the greater is the cost to feed and house them. These extended grow-out periods also have strong adverse effects on the behaviour of the fish (as outlined above). Therefore, a balance must be found between the benefits of long-term captivity on mortality and the disadvantages of behavioural deficits. Pre-release training can address this problem to some extent, but work in this area is still very much in its infancy (Jarvi and Uglem 1993;Wiley et al.1993; Brown and Smith 1998; Brown and Laland 2001) and has yet to be applied on a large scale.

\section{Economic feasibility}

There are currently few examples of restocking that are considered an economic success although the majority have yet to be fully assessed. Inland stocking, particularly in Asia, is often earmarked as a prime example of the success of stocking. Many examples of stocking in reservoirs and ox-bow lakes are often referred to as 'cost-e!ective' (Welcomme and Bartley 1998). Thai reservoirs, for example, are heavily stocked and the stocked fish are thought to contribute to $\$ 2$ million worth of carp captured each year. Closer inspection, however, reveals that the relative contribution of the stocked fish to the fishery has not yet been evaluated (Bhukaswan 1988, cited in Welcomme and Bartley 1998). Only the chum salmon and perhaps the red sea bream (Pagrus major) release programmes, in Japan, appear to have been economically successful, primarily because the cost of production is so low. Even the salmon success may, in fact, have resulted from improvements in oceanic conditions because similar increases in populations that are not supplemented from hatcheries have been observed in North America (Bigler et al.1996).

From a purely economic perspective, increased returns to the fishery would offset some of the costs associated with improving production and release methods similar to those outlined above (Behnke 1989). For example, if the probability of post-release survival could be doubled by changing rearing or releasing protocols at a cost of halving the total output of hatchery-reared juveniles, then such improvements should make little difference to the economic viability of hatcheries. With this in mind, hatcheries in Japan are now beginning to shift their focus towards producing fewer, higher quality juveniles for release (Fushimi 2001).

Models investigating the economic feasibility of releasing hatchery-reared cod indicate that in order to break even, a survival rate (i.e. survival until recruitment into the fishery) of $28 \%$ is required if 36 -week-old juveniles are released (Wilson et al. 1998). This figure is far beyond anything that has been realized to date, although Kristiansen (1999) reports survival rates of $23 \%$ in the first year if juveniles are released at $23 \mathrm{~cm}$. Perhaps the introduction of the techniques discussed above could close the gap between current survival rates and those required in order to break even. The economic data for the fishing industry as a whole suggests that economic success can hardly be considered a fair benchmark with which to judge the economic validity of altering restocking practices. Given people's insatiable appetite for fish, one must consider how much we are willing to pay for the continued privilege of catching and eating wild fish.

\section{Conclusion}

Fisheries scientists have known about the deficits in behaviour of hatchery-reared fish and the resultant poor survivorship in the wild for some time. Whilst there remain considerable gaps in our knowledge about the exact causes of post-release mortality, it is clear, based on our current level of understanding, that significant improvements could be made by rethinking the ways fish are reared, prepared for release and eventually liberated. The conservation reintroduction literature provides a guide as to the types of 
protocols that could be tested by fisheries researchers, and the data from fisheries releases could provide important feedback into the design of reintroduction programmes.

Improving fish culture methods should be considered a priority for future restocking programmes, both for fisheries and conservation purposes. The smallest improvements in the proportion of fish surviving to adulthood could result in substantial gains in absolute numbers of individuals entering the fishery. These gains would offset any increase in the price of production resulting from improved techniques such as environmental enrichment, life-skills training, or soft release. Many of the suggestions outlined above could be implemented relatively easily and may provide large improvements in post-release survival. The necessary measures need not be time-consuming or expensive.

Available data indicate that any training procedures need only be short-lived due to the rapid learning and reasonable retention periods displayed by fish. This suggests that training could take place in a brief bout just prior to release, periodically during development, or even in an acclimatization holding pen at the release site. The benefits of simple habitat enrichment procedures are already clear to see in the conservation and fish literature, and should soon be implemented by hatcheries on a large scale. The shoaling behaviour of some species of fish makes it possible to take advantage of social learning processes in order to increase the efficiency and efficacy of any training methods. Finally, we highlight the need for a greater understanding of the behavior and ecology of commercial species and call for closer monitoring of hatchery releases so that their success may be gauged and areas for fertile future research brought to light.

\section{Acknowledgements}

We thank two anonymous referees for their helpful contributions and suggestions. Culum Brown was funded by a BBSRC research grant and Rachel L. Day by a BBSRC studentship.

\section{References}

Abdolhay, H. (1996) Aquaculture and development in the Islamic Republic of Iran. In: Proceedings of the Working Group on Aquaculture, Indian Ocean Fishery Commission Committee for the Development and Management of the Fishery Resources of the Gulf,1996. Egypt.

Agersborg, H.P.K. (1934) Qualitative and quantitative analysis of foods for salmonids reared artificially. Transactions of the American Fisheries Society 64, 435-442.

Alcock, J. (1993) Animal Behaviour: an Evolutionary Approach. Sinauer Associates Inc., Sunderland Mass, 540pp.

Andrews, C. and Kaufman, L. (1994) Captive breeding programmes and their role in fish conservation. In: Creative Conservation: Interactive Management of Wild and Captive Animals (eds P.J.S. Olney, G.M. Mace and A.T.C. Feistner). Chapman \& Hall, London, pp.338-351.

Bachman, R.A. (1984) Foraging behaviour of free ranging wild and hatchery brown trout in a stream. Transactions of the American Fisheries Society 113, 1-32.

Beamish, R.J., Thompson, B.L. and McFarlane, G.A. (1992) Spiny dogfish predation on chinook and coho salmon and the potential effects on hatchery-produced salmon. Transactions of the American Fisheries Society 37, 805-811. 
Beck, B.B., Kleiman, D.G., Dietz, J.M., Castro, I., Carvalho, C., Martins, A. and Rettberg-Beck, B. (1991) Losses and reproduction in reintroduced golden lion tamarins (Leontopithecus rosalia). Dodo Jersey Wildlife Preservation Trust 27, 50-61.

Beck, B.B., Rapaport, L.G., Stanley Price, M.R. and Wilson, A.C. (1994) Reintroduction of captive-born animals. In: Creative Conservation: Interactive Management of Wild and Captive Animals (eds P.J.S. Olney, G.M. Mace and A.T.C. Feistner). Chapman \& Hall, London, pp.264-286.

Behnke, R.J. (1989) Summary of progress in wild trout management: 1979-1984. In: Wild Trout IV, (eds F. Richardson and R. Hamre). Trout Unlimited, Virginia, Vienna, pp. 12-17.

Berejikian, B.A. (1995) The effects of hatchery and wild ancestry and experience on the relative ability of steelhead trout fry (Oncorhynchus mykiss) to avoid a benthic predator. Canadian Journal of Fisheries and Aquatic Science 52, 2476-2482.

Berejikian, B.A., Mathews, S. and Quinn, T. (1996) Effects of hatchery and wild ancestry and rearing environments on the development of agonistic behavior in steelhead trout (Oncorhynchus mykiss) fry. Canadian Journal of Fisheries and Aquatic Science 53, 2004-2014.

Berejikian, B.A., Smith, R.J.F.,Tezak, E.P., Schroder, S.L. and Knudsen, C.M. (1999) Chemical alarm signals and complex hatchery rearing habitats affect anti-predator behavior and survival of chinook salmon (Onchorhynchus tshawytsha) juveniles. Canadian Journal of Fisheries and Aquatic Science 56, 830-838.

Berejikian, B.A., Tezak, E.P., Flagg, T.A., LaRae, A.L., Kummerow, E. and Mahnken, C.V.W. (2000) Social dominance, growth, and habitat use of age-0 steelhead (Oncorhynchus mykiss) grown in enriched and conventional hatchery rearing environments. Canadian Journal of Fisheries and Aquatic Science 57, 628-636.

Biggins, D.E. and Thorne, E.T. (1994) Management of an endangered species: the black-footed ferret. In: An Introduction to Conservation Biology (eds G. Me!e and R. Carroll). Sinauer Associates Inc., Sunderland Mass, pp. 369-374.

Bigler, B.S.,Welch, D.W. and Helle, J.H. (1996) A review of size trends among North Pacific salmon (Oncorhynchus spp). Canadian Journal of Fisheries and Aquatic Science 53, 455-465.

Blaxter, J.H.S. (2000) The enhancement of marine fish stocks. Advances in Marine Biology 38, 2-54.

Bolhuis, J.J. (1991) Mechanisms of avian imprinting: a review. Biological Reviews of the Cambridge Philosophical Society 66, 303-345.

Box, H.O. (1991) Training for life after release: simian primates as examples. Symposia of the Zoological Society of London 62, 111-123.

Brown, C. and Laland, K.L. (2001) Social learning and life skills training for hatchery reared fish. Journal of Fish Biology 59, 471-493.

Brown, G. and Smith, R. (1996) Foraging trade-offs in fathead minnows (Pimephales promelas, Osteichthyes, Cyprinidae): acquired predator recognition in the absence of an alarm response. Ethology 102, 776-785.

Brown, G.E. and Smith, R.J.F. (1998) Acquired predator recognition in juvenile rainbow trout (Oncorhynchus mykiss): conditioning hatchery-reared fish to recognize chemical cues of a predator. Canadian Journal of Fisheries and Aquatic Sciences 55, 611-617.

Brown, C. and Warburton, K. (1999) Differences in timidity and escape responses between predatornaïve and predator- sympatric rainbowfish populations. Ethology 105, 491-502.

Buchholz, R. and Clemmons, J.R. (1997) Behavioural variation: a valuable but neglected biodiversity. In: Behavioural Approaches to Conservation in the Wild (eds J.R. Clemmons and R. Buchholz). Cambridge University Press, Cambridge, pp.181-208.

Butler,R.L. (1981) Relationships of trout behavior and management: hatchery production and construction. In: Proceedings of the Bio-Engineering Symposium of Fish Culture (eds L.J. Allen and E.C. Kinney). American Fisheries Society, Fish Culture Section, Bethesda, Maryland, pp.97103. 
Caballero, C. and Castro, J.J. (1999) Effect of residence and size asymmetries upon the agonistic interactions between juvenile white-seabream (Diploduss argus cadenati de la Paz, Bauchot and Daget,1974). Aggressive Behaviour 25, 297-303.

Carlstead, K. (1996) Effects of captivity on the behaviour of wild mammals. In: Wild Mammals in Captivity: Principles and Techniques (eds D.G. Kleiman, M. Allen, K.Thompson, S. Lumpkin and H. Harris). University of Chicago Press, Chicago, pp.317-333.

Caro, T. (1999a) Behavioural Ecology and Conservation Biology. Oxford University Press, Oxford,582 pp.

Caro, T. (1999b) The behavior-conservation interface. Trends in Ecology and Evolution 14, 366-369.

Carpenter, J.W., Gabel, R.R. and Goodwin, J.G., Jr (1991) Captive breeding and reintroduction of the endangered masked bobwhite. Zoo Biology 10, 439-449.

Chilcote, M.W., Leider, S.A. and Loch, J.J. (1986) Differential reproductive success of hatchery and wild summer run steelhead under natural conditions. Transactions of the American Fisheries Society 117, 432-443.

Clemmons, J.R. and Buchholz, R. (1997) Behavioural Approaches to Conservation in the Wild. Cambridge University Press, Cambridge, $398 \mathrm{pp}$.

Coleman, F.,Travis, J. and Thistle, A.B. (1998) Marine stock enhancement: a new perspective. Bulletin of Marine Science 62, 303.

Cowx, I.G. (1998) Stocking and Introductions of Fish. Fishing News Books, Blackwell Science, Oxford, $464 \mathrm{pp}$.

Cresswell, R.C. and Williams, R. (1983) Post-stocking movements and recapture of hatchery-reared trout released into flowing water - effect of prior acclimation to flow. Journal of Fish Biology 23, 265276.

Croy, M.I. and Hughes, R.N. (1991) The role of learning and memory in feeding behaviour of the fifteenspined stickleback (Spinachia spinachia L.). Animal Behaviour 41, 149-160.

Csanyi, V. and Doka, A. (1993) Learning interactions between prey and predator fish. Marine Behaviour and Physiology 13, 63-78.

Derrickson, S.R. (1986) A cooperative breeding program for the Guam rail (Rallus owstoni). In: American Association of Zoological Parks and Aquariums Annual Proceedings. American Association of Zoological Parks and Aquariums, Wheeling, pp.223-240.

Derrickson, S.R. and Snyder, N.F.R. (1992) Potentials and limits of captive breeding. In: New World Parrots in Crisis: Solutions from Conservation Biology (eds S.R. Beissinger and N.F.R. Snyder). Smithsonian Institution Press, Washington, pp.133-163.

Deverill, J.I., Adams, C.E. and Bean, C.W. (1999) Prior residence, aggression and territory acquisition in hatchery-reared and wild brown trout. Journal of Fish Biology 55, 868-875.

Dill, L.M. and Fraser, A.H.G. (1984) Risk of predation and the feeding behavior of juvenile coho salmon (Oncorhynchus kisutch). Behavioural Ecology Sociobiology 16, 65-71.

Dobrott, S.R. (1993) Masked Bobwhite Recovery Plan. Region 2 (ed. W.P. Kuvlesky Jr). US Fish and Wildlife Service, Alberquerque, NM.

Doyle, R.W., Perez-Enriquez, R.,Takagi,M. andTaniguchi, N. (2001) Selective recovery of founder genetic diversity in aquacultural broodstocks and captive, endangered fish populations. Genetica 111, 291-304.

Ejike, C. and Schreck, C.B. (1980) Stress and social hierarchy rank in coho salmon. Transactions of the American Fisheries Society 109, 432-426.

Embody, G.C. and Gordon, M. (1924) A comparative study of natural and artificial foods of brook trout. Transactions of the American Fisheries Society 64,185-200.

Ersbak, K. and Haase, B.L. (1983) Nutritional deprivation after stocking as a possible mechanism leading to mortality in stream-stocked brook trout. North American Journal of Fisheries Management 3, 142-151. 
Fenderson, O.C. and Carpenter, M.R. (1971) Effects of crowding on the behaviour of juvenile hatchery and wild landlocked Atlantic salmon (Salmo salar L.). Animal Behaviour 19, 439-447.

Fish, F.F. (1940) An evaluation of trout culture. Transactions of the American Fisheries Society 69, 85-89.

Flagg, T.A., Mahnken, C.V.W. and Johnson, K.A. (1995) Captive broodstocks for the recovery of Snake River sockeye salmon. American Fisheries Society Symposium 15, 81-90.

Fraser, J. (1974) An attempt to train hatchery-reared brook trout to avoid predation by common loon. Transactions of the American Fisheries Society 103, 815-818.

Furuta, S. (1996) Predation of juvenile Japanese flounder (Paralichthys olivaceus) by diurnal piscivorous fish: field observations and laboratory experiments. In: Survival Strategies in Early Life Stages of Marine Resources (eds Y. Watanabe,Y.Yamashita and Y. Oozeki). A.A. Balkema, Rotterdam, pp.285-294.

Fushimi, H. (2001) Production of juvenile marine finfish for stock enhancement in Japan. Aquaculture 200, 33-53.

Ginetz, R.M. and Larkin, P.A. (1976) Factors affecting rainbow trout (Salmo gairdneri) predation on fry of sockeye salmon (Oncoryhnchus nerka). Journal of the Fisheries Research Board of Canada 33, 19-24.

Godin, J.J. (1978) Behaviour of juvenile pink salmon (Oncorhynchus gorbuscha Walbaum) toward novel pre: influence of ontogeny and experience. Environmental Biology of Fishes 3, 261-266.

Goodyear, C.P. (1973) Learned orientation in the predator avoidance behaviour of mosquito fish, Gambusia affinis. Behaviour 45, 191-224.

Gosling, L.M. and Sutherland, W.J. (2000) Behaviour and Conservation. Cambridge University Press, Cambridge, 438pp.

Gotceitas, V. and Godin, J.J. (1993) Effects of aerial and instream threat of predation in foraging by juvenile Atlantic salmon (Salmo salar). In: Production of Juvenile Salmon, Salmo Salar, in Natural Waters, Vol. 118 (eds R.J. Gibson and R.E. Cutting). Canadian Special Publications of Fisheries and Aquatic Sciences, pp.35-41.

Griffin, A.S., Blumstein, D.T. and Evans, C.S. (1999) Training captive-bred or translocated animals to avoid predators. Conservation Biology 14, 1317-1326.

Guinet, C. and Bouvier, J. (1995) Development of intentional stranding hunting techniques in killer whale (orcinusorca) calves at crozet archipelago. Canadian Journal of Zoology 73, 27-33.

Haskell, D.C. (1965) Are we looking in the right direction in fisheries research? Progressive Fish Culturist 27, 105-107.

Hojesjo, J., Johnsson, J.I., Petersson, E. and Jarvi,T. (1998) The importance of being familiar: individual recognition and social behaviour in sea trout (Salmo trutta). Behavioural Ecology 9, 445-451.

Hossain, M.A.R.,Tanaka, M. and Masuda, R. (2001) Predator-prey interaction between hatchery-reared Japanese flounder juvenile, Paralichthys olivaceus, and sandy shore crab, Matuta lunaris: daily rhythms, anti-predator conditioning and starvation. Journal of Experimental Marine Biology and Ecology 267, 1-14.

Howell, B.R. (1994) Fitness of hatchery-reared fish for survival in the sea. Aquaculture and Fisheries Management 25 (Suppl.1), 3-17.

Howell, B.R. and Baynes, S.M. (1993) Are hatchery-reared sole equipped for life in the sea? ICESCM1993/F 33 SESSR.

Hughes, R.N., Kaiser, M.J., Mackney, P.A. and Warburton, K. (1992) Optimizing foraging behaviour through learning. Journal of Fish Biology 41 (Suppl. B), 77-91.

IUCN Position Statement on Translocation of Living Organisms (1987) http://www.iucnorg.ac.psiweb.com/themes/ssc/pubs/policy/transe.htm (last accessed February 2002).

IUCN/SSC Guidelines for Reintroductions (1995) http://www.iucnorg.ac.psiweb.com/themes/ssc/pubs/policy/reinte.htm(last accessed Febuary 2002). 
Jarvi, T. (1990) Cumulative acute physiological stress in Atlantic salmon smolts: the effect of osmotic imbalance and the presence of predators. Aquaculture 89, 337-350.

Jarvi,T. and Uglem, I. (1993) Predator training improves the anti-predator behaviour of hatchery reared Atlantic salmon (Salmo salar) smolts. Nordic Journal of Freshwater Research 68, 63-71.

Johnsson, J.J. (1993) Big and brave: size selection affects foraging under predation risk in juvenile rainbow trout (Oncorhynchus mykiss). Canadian Journal of Zoology 45, 1219-1225.

Jokikokko, E. (1999) Density of brown trout, Salmo trutta L.\& Atlantic salmon, Salmo salar L., parr after point and scatter stocking of fry. Fisheries Management and Ecology 6, 475-486.

Jonssonn, S., Brannas, E. and Lundqvist, H. (1999) Stocking of brown trout, Salmo trutta L.: effects of acclimatization. Fisheries Management and Ecology 6, 459-473.

Kanayama, Y. (1968) Studies of the conditional reflex in lower vertebrates: defensive conditioned reflex of chum salmon fry in a group. Marine Biology 2, 77-87.

Kanayama,Y. and Tuge, $\mathrm{H}$. (1968) The use in fisheries of (elaborated) conditioned reflex in young chum salmon. Problems of Ichthyology 6, 834-837.

Kanid'hev, K.C., Kostyunin, G.M. and Salmin, S.A. (1970) Hatchery propagation of the pink and chum salmons as a means of increasing the salmon stocks of Sakhalin. Journal of Ichthyology 10, 249259.

Kaya, C.M. and Jeanes, E.D. (1995) Retention of adaptive rheotactic behaviour by F1 fluvial Arctic grayling. Transactions of the American Fisheries Society 124, 453-457.

Kieffer, J.D. and Colgan, P.W. (1992) The role of learning in fish behaviour. Reviews in Fish Biology and Fisheries 2, 125-143.

Kleiman,D.G. (1989) Reintroduction of captive mammals for conservation. Bioscience 39, 152-161.

Kleiman, D.G. (1996) Reintroduction Programs. In: Wild Mammals in Captivity: Principles and Techniques (eds D.G. Kleiman, M. Allen, K.Thompson, S. Lumpkin and H. Harris). University of Chicago Press, Chicago, pp. 297-305.

Kleiman, D.G., Beck, B.B., Dietz, J.M., Dietz, L.A., Ballou, J.B. and Coimbra-Filho, A.C. (1986) Conservation program for the golden lion tamarins: captive rearing and management, ecological studies, education strategies and reintroduction. In: Primates: the Road to Self-sustaining Populations (ed. K.Benirschke). Springer Verlag, NewYork, pp.959-979.

Kleiman, D.G., Stanley, M.R. and Beck, B.B. (1994) Criteria for reintroductions. In: Creative Conservation: Interactive Management of Wild and Captive Animals (eds P.J.S. Olney, G.M. Mace and A.T.C. Feistner). Chapman \& Hall, London, pp.287-300.

Korner, K.E., Lutjens, O., Parzefall, J. and Schlupp, I. (1999) The role of experience in mating preferences of the unisexual Amazon molly. Behaviour 136, 257-268.

Kristiansen,T.S. (1999) Enhancement studies of costal cod (Gadus morhua L.) in Nord-Trondelag, Norway. In: Stock Enhancement and Sea Ranching (eds B.R. Howell, E. Moksnessand and T. Svasand). Fishing News Books, Blackwell Science Ltd, Oxford, pp.277-292.

Lagardere, J.P., Ducamp, J.J., Frikha, L. and Sperandio, M. (1988) Ultrasonic tracking of common sole juveniles (Solea vulgaris Quensel, 1806) in a salt marsh: methods and fish response to some environmental factors. Journal of Applied Ichthyology 4, 87-96.

Leach, G.C. (1926) Discussion in symposium on fish culture. Transactions of the American Fisheries Society 56, 153-154.

Leber, K.M., Arce, S., Sterritt, D.A. and Brennan, N.P. (1996) Marine stock-enhancement potential in nursery habitats of striped mullet, Mugil cephalus, in Hawaii. Fishery Bulletin 94, 452-471.

Leider, S.A., Hulett, P.L., Loch, J.J. and Chilcote, M.W. (1990) Electrophoretic comparisons of the reproductive success of naturally spawning transplanted and wild steelhead trout through the returning adult stage. Aquaculture 88, 239-252.

Leon, K.A. (1975) Improved growth and survival of juvenile Atlantic salmon (Salmo salar) hatched in drums with a labyrinthine plastic substrate. Progressive Fish Culturist 37,158-163. 
Leonard, J.W. and Cooper, E.L. (1941) Experimenters favour conditioning trout before planting. Progressive Fish Culturist 54, 38.

Lepage, O., Overli, O., Petersson, E., Jarvi, T. and Winberg, S. (2000) Differential stress coping in wild and domesticated sea trout. Brain Behaviour and Evolution 56, 259-268.

Lewis, J.C. (1990) Captive propagation in the recovery of whooping cranes. Endangered Species Update 8, 46-48.

$\mathrm{Li}, \mathrm{J}$. (1999) An appraisal of factors constraining the success of fish stock enhancement programmes. Fisheries Management and Ecology 6, 161-169.

Lindburg, D.G. (1992) Are wildlife reintroductions worth the cost? Zoo Biology 11, 1-2 (Editorial).

Lord, R.F. (1934) Hatchery trout as foragers and game fish. Transactions of the American Fisheries Society 64, 339-345.

Lorenz, K.Z. (1952) King Solomon's Ring. Crowell, NewYork, 220 pp.

Magurran, A.E. (1990) The inheritance and development of minnow anti-predator behaviour. Animal Behaviour 39, 834-842.

Maloney, R.F. and McLean, I.G. (1995) Historical and experimental learned predator recognition in freeliving New Zealand robins. Animal Behaviour 50, 1193-1201.

Masuda, R. and Tsukamoto, K. (1998) Stock enhancement in Japan: review and perspective. Bulletin of Marine Science 62, 337-358.

Maynard, D., Flagg, T. and Mahnken, C. (1995) A review of semi-culture strategies for enhancing the post-release survival of anadromous salmonids. American Fisheries Society Symposium 15, 307314.

Maynard, D.J., McDowell, G.C., Tezak, E.P. and Flagg, T.A. (1996) Effects of diets supplemented with live food on the foraging behaviour of cultured fall chinook salmon. Progressive Fish Culturist 58, 187-191.

McLean, I.G. (1997) Conservation and the ontogeny of behaviour. In: Behavioural Approaches to Conservation in the Wild (eds J.R. Clemmons and R. Buchholz). Cambridge University Press, Cambridge, pp.132-156.

McLean, I.G., Lundie-Jenkins, G. and Jarman, P.J. (1996) Teaching an endangered mammal to recognise predators. Biological Conservation 87, 123-130.

McNeil, W. (1991) Expansion of cultured Pacific salmon into marine ecosystems. Aquaculture 98, 173183.

Mesa, M.G. (1981) Variation in feeding, aggression, and position choice between hatchery and wild cutthroat trout in an artificial stream. Transactions of the American Fisheries Society 120, 723727.

Mesick, C.F. (1988) Effects of food and cover on numbers of Apache and brown trout establishing residence in artificial stream channels. Transactions of the American Fisheries Society 117, 421431.

Metcalf, N.B., Huntingford, F.A. and Thorpe, J.E. (1987) The influence of predation risk on the feeding motivation and foraging strategy of juvenile Atlantic salmon. Animal Behaviour 35, 901-911.

Miller, R.B. (1954) Comparative survival of wild and hatchery-reared cutthroat trout in a stream. Transactions of the American Fisheries Society 83, 120-130.

Miller, B., Reading, R. and Forest, S. (1996) Prairie Night: Black Footed Ferrets and the Recovery of Endangered Species. Smithsonian Institution Press, Washington, DC, 320pp.

Mineka, S. and Cook, M. (1988) Social learning and the acquisition of snake fear in monkeys. In: Social Learning: Psychological and Biological Perspectives (eds T.R. Zentall and B.G. Galef). Erlbraum, Hillsdale, NJ, pp. 51-75.

Mirza, R.S. and Chivers, D.P. (2000) Predator-recognition training enhances survival of brook trout: evidence from laboratory and field-enclosure studies. Canadian Journal of Zoology 78, 21982208. 
Morgan-Davies, A.M. (1980) Translocating crocodiles. Oryx 15, 371-373.

Naeslund, I. (1992) Survival and distribution of pond and hatchery-reared 0+ browntrout, Salmo trutta L., released in a Swedish stream. Aquaculture and Fisheries Management 23, 477-488.

Nickelson, T.E., Solazzi, M.F. and Johnson, S.L. (1986) Use of hatchery coho salmon (Oncorhynchus kistuch) pre-smolts to rebuild wild populations in Oregon coastal streams. Canadian Journal of Fisheries and Aquatic Sciences 43, 2443-2449.

Nickleson, T.E. (1986) Influences of upwelling, ocean temperature and smolt abundance in marine survival of coho salmon (Oncorhynchus kistuch) in the Oregon production area. Canadian Journal of Fisheries and Aquatic Science 43, 527-535.

Olla, B.L. and Davis, M.W. (1989) The role of learning and stress in predator avoidance of hatchery reared coho salmon (Oncorhynchis kisutch) juveniles. Aquaculture 76, 209-214.

Olla, B.L., Davis, M.W. and Ryer, C.H. (1994) Behavioural deficits in hatchery-reared fished: potential effects on survival following release. Aquaculture and Fisheries Management 25 (Suppl.1), 19-34.

Olla, B.L., Davis, M.W. and Ryer, C.H. (1998) Understanding how the hatchery environment represses or promotes the development of behavioural survival skills. Bulletin of Marine Science 62, 531-550.

Olla, B.L., Davis, M.W. and Schreck, C.B. (1992) Comparison of predator avoidance capabilities with corticosteroid levels induced by stress in juvenile coho salmon. Transactions of the American Fisheries Society 121, 544-547.

Olney, P.J.S., Mace, G.M. and Feistner, A.T.C. (1994) Creative Conservation: Interactive Management of Wild and Captive Animals. Chapman \& Hall, London, 517 pp.

Paszkowski, C.A. and Olla, B.L. (1985) Foraging behaviour of hatchery produced coho salmon (Oncorhynchus kisutch) smolts on live prey. Canadian Journal of Fisheries and Aquatic Sciences 42, 1915-1921.

Patten, B.G. (1977) Body size and learned avoidance as factors affecting predation on coho salmon, Oncorhynchus kisutch, fry, by torrent sculpin, Cottus rhitheus. Fisheries Bulletin US Department Commerce Natn Oceanic Atmos Adm 75, 457-495.

Pearcy, W.G. (1992) Ocean Ecology of North Pacific Salmonids. University of Washington Press, Seattle, 179 pp.

Phillips, M.K., Smith, R., Henry, V.G. and Lucash, C. (1995) Red wolf reintroduction program. In: Ecology and Conservation of Wolves in a Changing World (eds L.N. Carbyn, S.H. Fritts and D.R. Seip). Canadian Circumpolar Institute, Edmonton, pp.157-168.

Provenza, F.D. and Cincotta, R.P. (1993) Foraging and predator avoidance in the hatchery-reared Pacific salmon: achievement of behavioural potential. In: The Importance of Feeding Behaviour for the Efficient Culture of Salmonid Fishes (eds J.E. Thorpe and F.A. Hintingford). The World Aquaculture Society, Baton Rouge, LA, pp. 5-12.

Pyanov, A.I. (1993) Fish learning in response to trawl fishing. ICES Marine Science Symposium 196,1216.

Reiriz, L., Nicieza, A.G. and Brana, F. (1998) Prey selection by experienced and naive juvenile Atlantic salmon. Journal of Fish Biology 53, 100-114.

Reisenbinchler, R.R. and McIntyre, J.D. (1977) Genetic differences in growth and survival of hatchery and wild steelhead trout, Salmo gairdneri. Journal of the Fisheries Resources Board of Canada 34, 123-128.

Ringler, N.H. (1979) Selective predation by drift feeding brown trout (Salmo trutta). Journal of the Fisheries Research Board of Canada 36, 392-403.

Ritter, J.A. and MacCrimmon, H.R. (1973) Influence of environmental experience on response of yearling rainbow trout (Salmo gairdneri) to black and white substrate. Journal of the Fisheries Research Board of Canada 30, 1740-1742.

Salvanes, A.G.V. (2001) Ocean Ranching. In: Encyclopedia of Ocean Sciences (eds J. Steele, K.K. Turkian and S.A. Thorpe). Academic Press, Vol.4, pp 1973-1982. 
Schreck, C.B., Olla, B.L. and Davis, M.W. (1997) Behavioural response to stress. In: Fish Stress and Health in Aquaculture (eds G. K. lawama, A.D. Pickering, J.P. Stumper and C.B. Schreck). Cambridge University Press, Cambridge, pp. 145-170.

Schulte, B.A. (2000) Social structure and helping behavior in captive elephants. Zoo Biology 19, 447-459.

Scott-Brown, J.M., Herrero, S. and Mamo, C. (1986) Monitoring of released swift foxes in Alberta and Saskatchewan: final report, 1986. Canadian Fish and Wildlife Service.

Secor, D.H. and Houde, E.D. (1998) Use of larval stocking in restoration of Chesapeake Bay striped bass. ICES Journal of Marine Science 55, 228-239.

Secor, D.H., Niklitschek, E.J., Stevenson, J.T., Gunderson, T.E., Minkkinen, S.P., Richardson, B., Florence, B., Mangold, M., Skjeveland, J. and Henderson-Arzapalo, A. (2000) Dispersal and growth of yearling Atlantic sturgeon, Acipenser oxyrinchus released into Chesapeake Bay. Fishery Bulletin 98, 800-810.

Shepherd, J. and Bromage, N. (1992) Intensive Fish Farming. Blackwell Scientific Publications, Oxford, $416 \mathrm{pp}$.

Shepherdson, D.J. (1994) The role of environmental enrichment in the captive breeding and reintroduction of endangered species. In: Creative Conservation: Interactive Management of Wild and Captive Animals (eds P.J.S. Olney, G.M.Mace and A.T.C. Feistner). Chapman \& Hall, London, pp.167-175.

Shepherdson, D.J., Carlstead, K., Mellen, J.D. and Seidensticker, J. (1993) The influence of food presentation on the behaviour of small cats in confined environments. Zoo Biology 12, 203-216.

Simpson, R. and Jackson, P. (1996) The Mary River Cod Research and Recovery Plan. Queensland Department of Primary Industries Fisheries Group, Australia.

Sosiak, A.J., Randall, R.G. and McKenzie, J.A. (1979) Feeding by hatchery-reared and wild Atlantic salmon (Salmo salar) parr in streams. Journal of the Fisheries Resources Board of Canada 36, 1408-1412.

Sproul, J.T. and Tominaga, O. (1992) An economic review of the Japanese flounder stock enhancement project in Ishikari Bay, Hokkaido. Bulletin of Marine Science 50, 75-88.

Stone, L. (1872) Trout culture. Proceedings of the American Fish Culturists' Association 1, 46-56.

Stradmeyer, L. and Thorpe, J.E. (1987) Feeding behaviour of wild Atlantic salmon, Salmo salar L., parr in mid- to late summer in a Scottish river. Aquaculture and Fisheries Management 18, 33-49.

Strange, R.J., Schreck, C.B. and Ewing, R.D. (1978) Cortisol concentrations in confined juvenile chinook salmon (Oncorhynchus tshawytscha). Transactions of the American Fisheries Society 107, 812819.

Stunz, G.W., Levin, P.S. and Minello, T.J. (2001) Selection of estuarine nursery habitats by wild-caught and hatchery-reared juvenile red drum in laboratory mesocosms. Environmental Biology of Fishes 61, 305-313.

Suboski, M.D. and Templeton, J.J. (1989) Life skills training for hatchery fish: social learning and survival. Fisheries Research (Amsterdam) 7, 343-352.

Svasand, T., Kristiansen, T.S., Pedersen, T., Salvanes, A.G.V., Engelsen, R., Naevdal, G. and Nodtvedt, M. (2000) The enhancement of cod stocks. Fish and Fisheries 1, 173-205.

Svasand, T., Skilbrei, O.T., van der Meeren, G.I. and Holm, M. (1989) Review of morphological and behavioural differences between reared and wild individuals: implications for sea-ranching of Atlantic salmon, Salmo salar L., Atlantic cod, Gadus morhua L. \& European lobster, Homarus gammarus L. Fisheries Management and Ecology 5, 1-18.

Swain, D.P. and Riddell, B.E. (1990) Variation in agnostic behaviour between newly emerged juveniles from hatchery and wild populations of coho salmon, Oncorhynchus kistuch. Canadian Journal of Fisheries and Aquatic Sciences 48, 1783-1791. 
Thompson, R.B. (1966) Effects of predator avoidance conditioning on the post-release survival rate of artificially propagated salmon. PhD Thesis, University of Seattle, WA, 156 pp. (cited in Jarvi and Uglem 1993).

Tsukamoto, K ., Kuwada, H., Hirokawa, J., Oya, M., Sekiya, S., Fujimoto, H. and Imaizumi, K. (1989) Size dependent mortality of red sea bream, Pargus major, juveniles released with fluorescent otolith tags in News Bay, Japan. Journal of Fish Biology 35A, 59-69.

Usher,M.L.,Talbot, C. and Eddy, F.B. (1991) Effects of transfer to seawater on growth and feeding Atlantic salmon smolts (Salmo salar L.). Aquaculture 94, 309-326.

Utter, F. (1998) Genetic problems of hatchery-reared progeny released into the wild, and how to deal with them. Bulletin of Marine Science 62, 623-640.

Vargus, A. and Anderson, S.H. (1998) Ontogeny of black-footed ferret predatory behaviour towards prairie dogs. Canadian Journal of Zoology 76, 1696-1704.

Vincent, R.E. (1960) Some influences of domestication upon three stocks of brook trout (Salvelinis fontinalis Mitchell). Transactions of the American Fisheries Society 89, 35-52.

Volpe, J.P., Anholt, B.R. and Glickman, B.W. (2001) Competition among juvenile Atlantic salmon (Salmo salar) and steelhead (Oncorhynchus mykiss): relevance to invasion potential in British Columbia. Canadian Journal of Fisheries and Aquatic Sciences 58,197-207.

Wallace,M.P. (2000) Retaining natural behaviour in captivity for reintroduction programmes. In: Behaviour and Conservation (eds L.M. Gosling and W.J. Sutherland). Cambridge University Press, Cambridge, pp.300-314.

Wallace, M.P. and Temple, S.A. (1987) Releasing captive-reared Andean condors to the wild. Journal of Wildlife Management 51, 541-550.

Ware, D.M. (1971) Predation by rainbow trout: the effect of experience. Journal of the Fisheries Research Board of Canada 28, 1847-1852.

Weber, P.G. and Weber, S.P. (1976) He effect of female colour, size dominance and early experience upon mate selection in male convict cichlids, Cichlasomanigrofasciatum Guenther (Pisces, Chichlidae). Behaviour 16, 116-135.

Welcomme, R.L. (1992) A history of international introductions of inland aquatic species. FAO Fisheries Technical Paper no.294. FAO, Rome, 318pp.

Welcomme, R.L. and Bartly, D.M. (1998) An evaluation of present techniques for the enhancement of fisheries. FAO Fisheries Technical Paper \#374. Department of Internal Development of the United Nations.

Wiley, R.W.,Whaley, R.A., Satake, J.B. and Fowden, M. (1993) An evaluation of the potential for training trout in hatcheries to increase post-stocking survival in streams. North American Journal of Fisheries Management 13, 171-177.

Wilson, J.A., Langton, R.W. and Van Orsdel, C. (1998) A model for the preliminary analysis of the economic feasibility of Atlantic cod enhancement in the Gulf of Maine (USA). Bulletin of Marine Science 62, 675-687.

Winton, J. and Hilborn, R. (1994) Lessons from supplementation of chinook salmon in British Columbia. North American Journal of Fisheries Management 14,1-13. 